\title{
DYNAMIC EFFECTS IN A COMPOSITE TWO-COMPONENT RODS WHICH APPEAR WHEN LOCAL FRACTURE OF THE MATRIX IS OCCURRED
}

\author{
Vitaly Ivanovich Kolchunov* \\ Southwest State University, Kursk, Russia \\ Sergey Yurievich Savin \\ Southwest State University, Kursk, Russia
}

\begin{abstract}
The article deals with the estimation of the dynamic increase of stresses in the element made of the composite two-component material such as reinforced concrete, that appears when local destruction of the concrete matrix (crack formation) occurs. When the brittle fracture of the concrete occurs the stresses acting in the stretched concrete are transmitted to the reinforcing bars instantaneously that leads to longitudinal oscillations. In this moment stresses acting in the reinforcing bars can be higher than ultimate stresses. Hence progressive collapse of a structure is possible. It is presented general solution of the forced longitudinal oscillations problem. Displacement and stress increment equations are given. General solution is illustrated by analysis of a progressive collapse of a largepanel folded shell when local destruction of concrete matrix in the tightening element occurs.
\end{abstract}

Key words: Longitudinal oscillations, Progressive collapse, Stresses, Matrix, Dynamics, Dynamic Effects, Concrete, Composition

\section{INTRODUCTION}

The buildings and structures that were built in the past decades were designed on the basis of the normative documents which acted at that time. However, when it requires the residual resource estimation or strengthening, engineers must apply current building codes and regulations, which have significantly expanded the range of possible loads and impacts, including emergency impacts. It is known that if the operating conditions in such a two-component material as reinforced concrete are violated, degradation processes in concrete and reinforcement are possible and, as a result, sudden brittle failure of the concrete matrix occurs. When it analyzes the resistance to progressive collapse of structural systems, which are made of reinforced concrete, in the cases of emergency situations caused by the sudden failure of one of the system's bearing elements $[01,02,03,04,05]$, it is necessary to research dynamical increasing of stresses in its elements. Quantitatively, these increases depend on a wide range of factors, such as the topology of the structural system, the location of the failure element, the level of loading of the system, and others. For reinforced concrete structures, as it is shown in [06], one of the most important factors is the composition of the material of the structure.

For this reason, the article describes the definition of dynamical increasing of stresses, which arising into the reinforcement of two-component composite rod elements when local brittle fracture of a concrete matrix occurs. When the brittle fracture of the concrete occurs, the stresses acting in the stretched concrete are transmitted to the reinforcement. Due to the instant transmission of these stresses the longitudinal oscillations arise in the reinforcing bar, and the magnitude of the dynamic stresses may exceed the design tensile strength of the steel.

In the monograph [01] and articles [06, 07] the solution of such problem was obtained in a quasistatic formulation based on the energy principles proposed by G.A. Geniev and etc. [08]. There is not solution of such problems in a dynamic formulation at this moment, although it can become a test for the verification of approximate solutions of a wide class of practically important problems. So, we consider the case of 
local fracture of a matrix in a centrally stretched composite rod element, using equations of the structure dynamics.

\section{RESEARCHES AND RESULTS}

Using the methodology of $[01,09,10]$, we obtain a differential equation for the forced longitudinal oscillations that arise in a two-component composite rod element when the matrix is suddenly destroyed. As a result two-component element is divided into at least three sections: only the reinforcing bar remains in the cross section with a crack and there are two reinforced concrete elements on the both sides of the crack. For the i-th section of such composite rod element, as it shown in the Figure 1, the partial differential equation of motion can be written in the form:
$E A_{i} \frac{\partial^{2} u}{\partial x^{2}}=\rho A_{i} \frac{\partial^{2} u}{\partial t^{2}}+P$,

Where $P$ is the externally applied force, $u$ is the displacement function, $\rho$ is the reduced density of the two-component material, $\mathrm{E}$ is the matrix deformation module of the element 2 , $i$ is the number of the rod element sections the crosssectional tensile stiffness of which is constant; $\mathrm{Ai}$ is the reduced cross-sectional area of the $\mathrm{i}$-th section; $x$ is the coordinate of the section; $T$ is time. It is should be noted that the force $P$, which is transmitted from the concrete matrix to the reinforcing bar at the moment of crack formation is written to the right side of equation (1) as the inertial force.

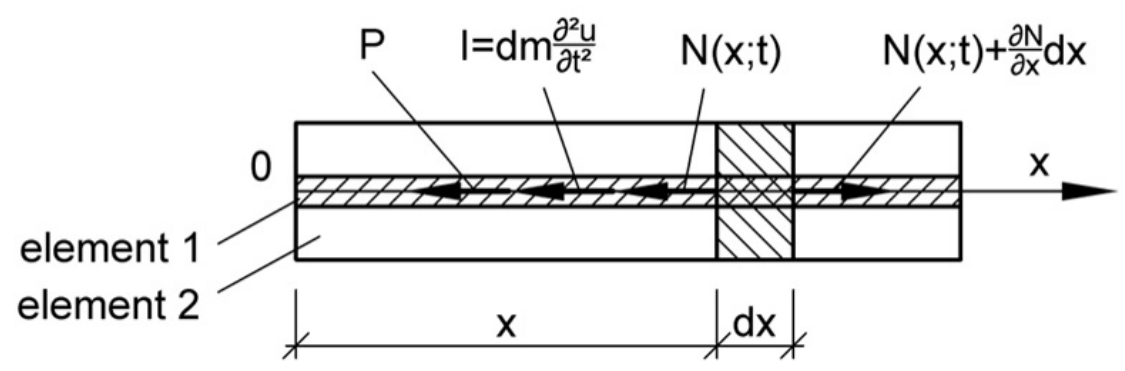

Figure 1: Dynamic equilibrium of an elementary region of a two-component rod element

We introduce dimensionless variables and parameters to obtain more general solution of the problem:

$\bar{p}_{i}=\frac{P}{E A_{i}}, \quad \bar{u}=\frac{u}{L}, \xi=\frac{x}{L}, \quad T=\frac{t}{L} \sqrt{\frac{E}{\rho}}$.

Then we obtain:

$$
\frac{\partial^{2} \bar{u}_{i}}{\partial \xi_{i}^{2}}=\frac{\partial^{2} \bar{u}_{i}}{\partial T^{2}}+\bar{p}_{i} .
$$

The solution of the inhomogeneous differential equation consists of the solution of the corresponding homogeneous equation and some particular solution.

\section{SOLUTION OF THE HOMOGENEOUS EQUATION}

$$
\frac{\partial^{2} \bar{u}_{i}}{\partial \xi_{i}^{2}}-\frac{\partial^{2} \bar{u}_{i}}{\partial T^{2}}=0
$$

We write the displacement function as $\bar{u}_{i}=U\left(\xi_{i}\right) e^{i \lambda t}$ to divide the variables. In this case we obtain:

$\ddot{U}\left(\xi_{i}\right)+\lambda^{2} U\left(\xi_{i}\right)=0$,

where $\lambda=\omega \cdot L \sqrt{\rho / E}, \omega-$ natural oscillation frequency.

Since the solution of the characteristic equation is the non-conjugate complex roots, then

$$
U\left(\xi_{i}\right)=C_{1 i} \cos \left(\lambda \xi_{i}\right)+C_{2 i} \sin \left(\lambda \xi_{i}\right)
$$

If this equation is differentiated by $\xi$, then the longitudinal force in the i-th element takes the form

$$
\begin{aligned}
& N_{i}=E_{i} A_{i} \dot{U}\left(\xi_{i}\right)=-E_{i} A_{i} \lambda C_{1 i} \sin \left(\lambda \xi_{i}\right) \cos \left(\lambda \xi_{i}\right)+ \\
& +E_{i} A_{i} \wedge C_{2 i} \cos \left(\lambda \xi_{i}\right) .
\end{aligned}
$$

Formulas (5) and (6) take a matrix form:

$X_{i}=Z_{i}\left(\lambda \xi_{i}\right) C_{i}$

Where $X$ is the matrix which characterizes displacements and forces in the section of the structural element, $\mathrm{C}$ is the matrix of coefficients

$Z_{i}\left(\lambda \xi_{i}\right)=\left(\begin{array}{cc}\cos \left(\lambda \xi_{i}\right) & \sin \left(\lambda \xi_{i}\right) \\ -E_{i} A_{i} \Lambda \sin \left(\Lambda \xi_{i}\right) & E_{i} A_{i} \Lambda \cos \left(\lambda \xi_{i}\right)\end{array}\right)$ 
If state of the system in the initial section of the $\mathrm{i}$-th segment is characterised by the matrix $\mathrm{XiO}$, then

$$
Z_{i}(0)=B_{i}=\left(\begin{array}{cc}
1 & 0 \\
0 & E_{i} A_{j} \Lambda
\end{array}\right)
$$

From (8) we obtain Ci

$$
C_{i}=B_{i}^{-1} X_{i 0}
$$

Substituting formula (8) into (7) we obtain the matrix of the arbitrary section state for the i-th section.

$X_{i}=V_{i}\left(\Lambda \xi_{i}\right) X_{i 0}$

where

$$
\begin{aligned}
& V_{i}\left(\lambda \xi_{i}\right)=Z_{i}\left(\lambda \xi_{i}\right) B_{i}^{-1}=\left(\begin{array}{cc}
\cos \left(\lambda \xi_{i}\right) & \sin \left(\lambda \xi_{i}\right) \\
-E_{i} A_{i} \lambda \sin \left(\lambda \xi_{i}\right) & E_{i} A_{i} \lambda \cos \left(\lambda \xi_{i}\right)
\end{array}\right) \\
& \left(\begin{array}{cc}
1 & 0 \\
0 & \frac{1}{E_{i} A_{i} \lambda}
\end{array}\right)=\left(\begin{array}{cc}
\cos \left(\lambda \xi_{i}\right) & \frac{1}{E_{i} A_{i} \lambda} \sin \left(\lambda \xi_{i}\right) \\
-E_{i} A_{i} \lambda \sin \left(\lambda \xi_{i}\right) & \cos \left(\lambda \xi_{i}\right)
\end{array}\right)
\end{aligned}
$$

The state vector of the end of the i-th section for $\xi_{i}=\bar{l}_{i}\left(\bar{l}_{i}=x_{i} / L\right)$ takes a torm:

$X_{i}=V_{i}\left(\eta_{i}\right) X_{i 0}, \quad \eta_{i}=\lambda I_{i}$,

Where $x i$ is the distance from the origin to the right end section of the i-th section.

Continuity equations of displacements and forces for the section $\xi=I_{i}$ of $i$ segment and $(i+1)$ segment have the form

$$
\begin{gathered}
U_{i}\left(I_{i}\right)=U_{i+1}\left(I_{i}\right), \\
E A_{i} \dot{U}_{i}\left(I_{i}\right)=E A_{i+1} \dot{U}_{i+1}\left(I_{i}\right) .
\end{gathered}
$$

Additional equations can be obtained from the boundary conditions

$$
U_{1}(0)=\dot{U}_{m}(1)=0 \text {. }
$$

In this case the state vector of the $\mathrm{m}$-th segment for $\xi \mathrm{m}=\mathrm{Im}$ :

$$
\begin{aligned}
& X_{m}=V\left(\eta_{m}\right) X_{m 0}=V\left(\eta_{m}\right) V\left(\eta_{m-1}\right) \cdot \ldots \cdot \\
& \ldots V\left(\eta_{1}\right) X_{10}=S_{m I_{m}} X_{10},
\end{aligned}
$$

where $\mathrm{S}(\mathrm{mlm}$ is the matrix that describes influence of initial section to the end section.

If we write $S(\mathrm{mlm})$ in the form
$S_{m \bar{I}_{m}}=\left(\begin{array}{ll}S_{11} & S_{12} \\ S_{21} & S_{22}\end{array}\right)$,

then

$$
\left(\begin{array}{l}
X_{m \bar{I}_{m}} \\
\dot{X}_{m \bar{l}_{m}}
\end{array}\right)=\left(\begin{array}{ll}
S_{11} & S_{12} \\
S_{21} & S_{22}
\end{array}\right)\left(\begin{array}{l}
X_{10} \\
\dot{X}_{10}
\end{array}\right) \text {. }
$$

Values of $\lambda$ for the corresponding forms of oscillations can be obtained approximately, if we substitute boundary conditions into the formula (11).

\section{GENERAL SOLUTION OF NON-HOMOGENOUS DIFFERENTIAL EQUATION}

We represent the general solution of the non-homogeneous equation (2) in the form of a series expansion in eigenfunctions $U i n(\xi)$ with unknown functions Qin (T) as coefficients:

$$
\bar{u}_{i}(\xi ; T)=\sum_{n=1}^{\infty} Q_{i n}(T) U_{i n}(\xi) \text {. }
$$

Solving equation (2) with respect to the equations (12) and (4) we obtain:

$$
\begin{aligned}
\sum_{n=1}^{\infty}\left(Q_{i n}(T) \frac{d^{2} U_{i n}(\xi)}{d \xi^{2}}-\right. & \left.\frac{d^{2} Q_{i n}(T)}{d T^{2}} U_{n}(\xi)\right)-\bar{p}_{i}= \\
& =\sum_{n=1}^{\infty}\left(\frac{d^{2} Q_{i n}(T)}{d T^{2}}+\lambda_{n}^{2} Q_{i n}(T)\right) U_{i n}(\zeta)-\bar{p}_{i}=0
\end{aligned}
$$

Multiplying equation (13) and Uin( $(\xi)$, integrating with respect to $\xi$ from li-1 to li and using the property of eigenmodes orthogonality, we obtain a differential equation for the functions Qin( $\mathrm{T})$ :

$$
\frac{d^{2} Q_{i n}(T)}{d T^{2}}+\lambda_{n}^{2} Q_{i n}(T)=R_{i n},
$$

where

$$
R_{i n}=\frac{\int_{\bar{T}_{i-1}}^{\bar{T}_{i}} \bar{p}_{i} U_{i n}(\xi) d \xi}{\int_{\bar{l}_{i-1}}^{\bar{l}_{i}} U_{i n}^{2}(\xi) d \xi}
$$

Integral of the equation (14) has the form

$$
Q_{i n}(T)=C_{3 i n} \cos \left(\lambda_{n} T\right)+C_{4 i n} \sin \left(\lambda_{n} T\right)+\frac{R_{i n}}{\lambda_{n}^{2}}
$$

Substituting formula (15) into (12) we obtain dynamic displacement function for i-thsegment of a composite rod for the situation when local fracture occurs suddenly. 
$\bar{u}(\xi ; T)=\sum_{n=1}^{\infty}\left[C_{3 i n} \cos \left(\lambda_{n} T\right)+C_{4 i n} \sin \left(\lambda_{n} T\right)+\right.$

$\left.+\frac{R_{i n}}{\lambda_{n}^{2}}\right] U_{i n}(\zeta)$.

It is should be applied initial conditions for $\mathrm{T}=0$ to obtain the parameters $\mathrm{C} 3 \mathrm{in}$ and C4in:

where

$$
\begin{gathered}
\bar{u}(\xi ; 0)=\bar{u}_{c m}(\xi),\left.\frac{\partial \bar{u}}{\partial T}\right|_{T=0}=0 . \\
\bar{u}_{c m}(\xi)=\bar{p}_{i} \cdot \xi L .
\end{gathered}
$$

thus, we obtain

$$
\begin{gathered}
C_{3 i n}=\frac{\int_{i=1}^{T_{i}} \bar{u}_{c m}(\xi) U_{i n}(\xi) d \xi}{\int_{i=1}^{T_{i}} U_{i n}^{2}(\xi) d \xi}-\frac{R_{i n}}{\lambda_{n}^{2}}, \\
C_{4 i n}=0.1
\end{gathered}
$$

Differentiating equation (16) with respect to $\xi$, we obtain the expression for the dynamic increments of the longitudinal force in the reinforcing bar when the local destruction of the concrete matrix occurred:

$$
\begin{aligned}
& \mathrm{N}(\xi ; \mathrm{T})=E A_{i} \sum_{\mathrm{n}=1}^{\infty}\left[C_{3 i n} \cos \left(\lambda_{n} T\right)+\right. \\
& \left.+C_{4 i n} \sin \left(\lambda_{n} T\right)+\frac{R_{\text {in }}}{\lambda_{n}^{2}}\right] \dot{U}_{\text {in }}\left(\xi_{i}\right),
\end{aligned}
$$

\section{DYNAMIC STRENGTH ANALYSIS OF A LARGE-PANEL FOLDED SHELL}

As an example, it can be considered the calculation of the dynamic increasing of stresses, that acting in the tightening element of a large-panel folded shell as it is shown in the figure 2, the constructive solution of which is given in [11, 12]. The initial characteristics of the construction materials have the follow values: concrete $\mathrm{B} 45, \mathrm{Rb}$,ser $=2.25 \mathrm{MPa}(\mathrm{\gamma b}=1)$, reinforcing bar class A-V (A800), Rs,ser $=785 \mathrm{MPa}$. Tightening section equals $h \times b=140 \times 110 \mathrm{~mm}$, length equals $L=24 \mathrm{~m}$. The prestressed reinforcement has area Asp $=6.158 \times 10-4 \mathrm{~m} 2$ (one reinforcing bar with diameter equals $28 \mathrm{~mm}$ ). The force of crack formation is Ncrc $=468.3 \mathrm{kN}$, that includes compression force P01 $=419.6 \mathrm{kN}$ (at initial controlled stress $\sigma s p=741.7 \mathrm{MPa}<0.95 \mathrm{Rs}$, ser in accordance with [13]). The force acting in the tightening element is caused by the external load $\mathrm{H}=475 \mathrm{kN}$. Since the force in the tightening element which is caused by external load is greater than the force of crack formation $\mathrm{H}=475$ $\mathrm{kN}>\mathrm{Ncrc}=468.3 \mathrm{kN}$, then a crack is formed in the element, i.e. there is a local destruction of the concrete matrix, and there are longitudinal oscillations in the reinforcing bar.

(a)

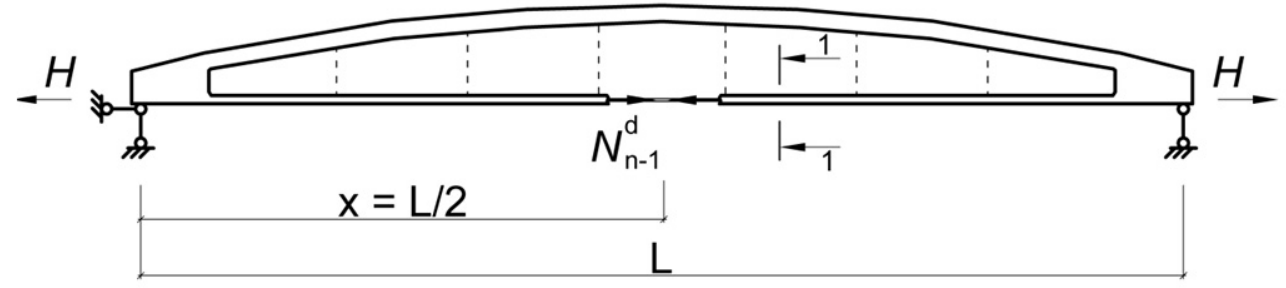

(b)
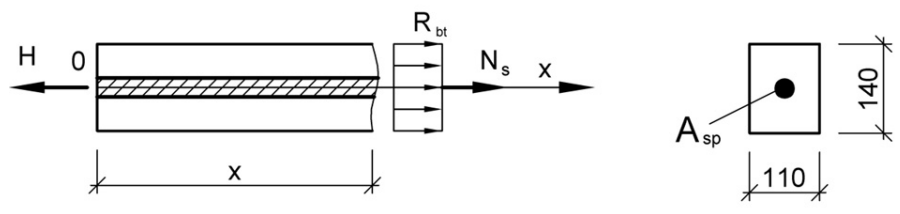

Figure 2: Large-panel folded shell: a) computationalmodel, b) forces in the danger section at the moment of a crack formation 
We suppose that the lower element of largepanel folded shell is divided into three segments at the moment of crack formation. These segments include only the reinforcing bar in the section with a crack and two reinforced concrete elements on both sides from the crack. Then we can find the forms of the natural longitudinal oscillations, using the relations (5) and (6) for the i-th section. The state vector of the first segment has the form:

$$
X_{1}\left(\xi_{1}\right)=V_{1}\left(\lambda_{n} \xi_{1}\right) X_{10}
$$

state vector of the second segment:

$$
X_{2}\left(\xi_{2}\right)=V_{2}\left(\lambda_{n} \xi_{2}\right) V_{1}\left(\eta_{1}\right) X_{10}
$$

state vector of the third segment:

$$
X_{3}\left(\xi_{3}\right)=V_{3}\left(\lambda_{n} \xi_{3}\right) V_{2}\left(\eta_{2}\right) V_{1}\left(\eta_{1}\right) X_{10}
$$

We introduce the following notation:

$$
\begin{gathered}
\Phi_{2}\left(\xi_{2}\right)=V_{2}\left(\lambda_{2} \xi_{2}\right) V_{1}\left(\eta_{1}\right) X_{10^{\prime}} \\
\Phi_{3}\left(\xi_{3}\right)=V_{3}\left(\lambda_{3} \xi_{3}\right) V_{2}\left(\eta_{2}\right) V_{1}\left(\eta_{1}\right) X_{10} .
\end{gathered}
$$

Then:

$$
\Phi_{i}\left(\xi_{i}\right)=\left(\begin{array}{ll}
\varphi_{11}\left(\lambda_{i} \xi_{i}\right) & \varphi_{12}\left(\lambda_{i} \xi_{i}\right) \\
\varphi_{21}\left(\lambda_{i} \xi_{i}\right) & \varphi_{22}\left(\lambda_{i} \xi_{i}\right)
\end{array}\right)
$$

The forms of oscillations of the segments take the form:

$$
\begin{aligned}
& U_{1 n}=U_{10} \cos \left(\lambda_{n} \xi_{1}\right)+\frac{1}{\lambda_{n}} \dot{U}_{10} \sin \left(\lambda_{n} \xi_{1}\right), \\
& U_{2 n}=U_{10} \varphi_{11}^{(2)}\left(\lambda_{n} \xi_{2}\right)+\dot{U}_{10} \varphi_{12}^{(2)}\left(\lambda_{n} \xi_{2}\right), \\
& U_{3 n}=U_{10} \varphi_{11}^{(3)}\left(\lambda_{n} \xi_{3}\right)+\dot{U}_{10} \varphi_{12}^{(3)}\left(\lambda_{n} \xi_{3}\right) .
\end{aligned}
$$

Variating $\lambda \mathrm{n}$ values we find that ones which satisfy the boundary conditions for the end sections of the tightening:

$$
X_{10}=0, N_{1}=\dot{X}_{10}=N_{c r c} N_{4}=\dot{X}_{m I_{m}}=0 \text {. }
$$

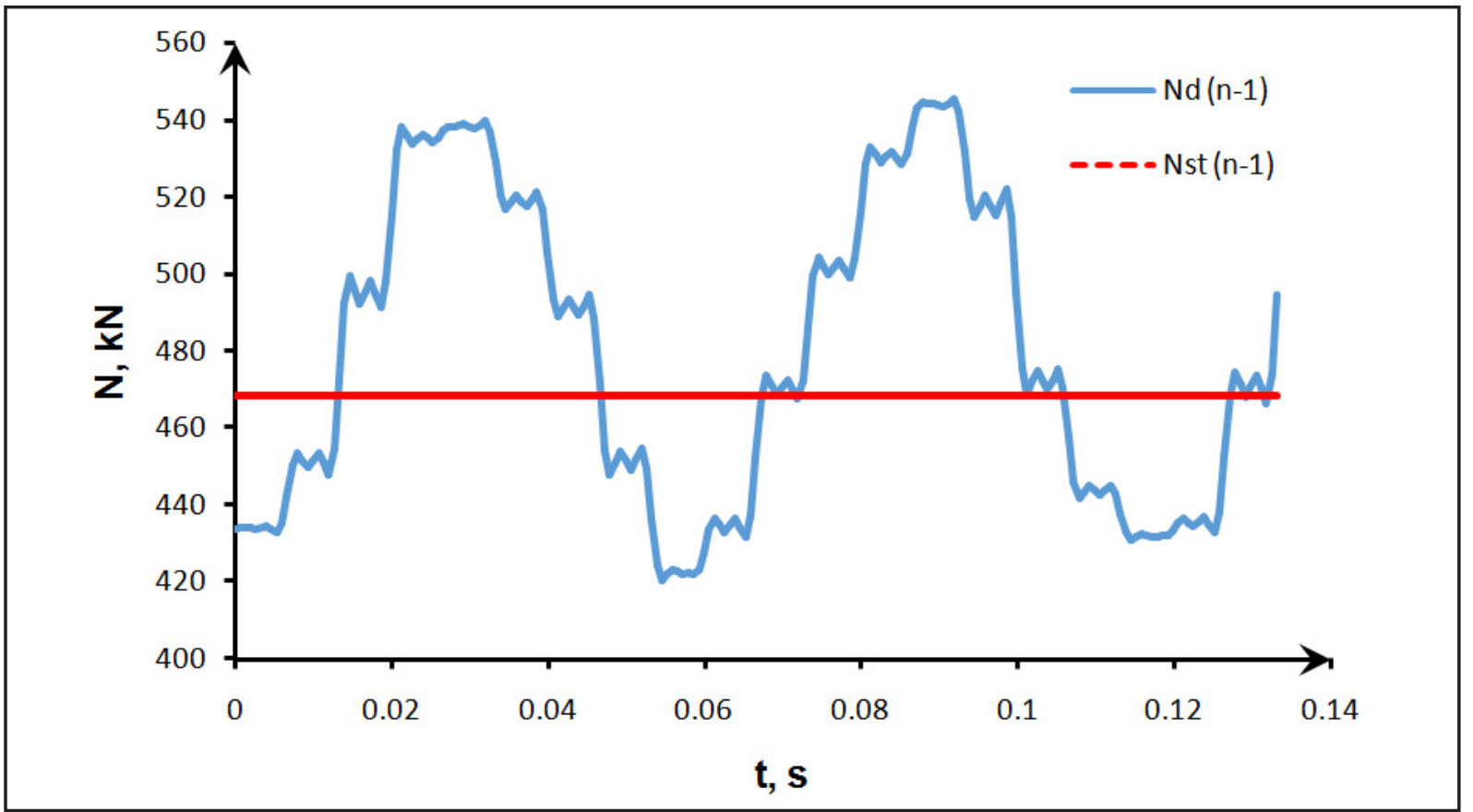

Figure 3: Relationship Nn-1d-t for the reinforcing bar (element 1) in the section

with a crack

Keeping the first ten forms of natural oscillations we find the values of the parameters C3in. Substituting these ones in (18), we obtain the dynamic forces which arising in the reinforcing bar when the sudden local destruction of the concrete matrix occurs. Relationship between dynamic force and time is shown in the Figure 3.

The nature of the graph of $\mathrm{Nn}-1 \mathrm{~d}-\mathrm{t}$ in the figure 3 is caused of superposition of the first ten oscillation modes. The greatest value of the dynamic longitudinal force in the reinforcing bar is $\mathrm{Nn}-1$ ${ }^{\wedge} \mathrm{d}=545.4 \mathrm{kN}$ (this one is achieved at the time $\mathrm{T}$ $=4.2(\mathrm{t}=0.028 \mathrm{~s})$. Hence the dynamic increasing factor to the reinforcing bar takes the value-

$$
\frac{N_{n-1}^{d}}{N_{n}^{s}}=\frac{545.4}{433.65}=1.258
$$


where $\mathrm{Nn}^{\wedge} \mathrm{s}=\mathrm{P} 01+2 \alpha \mathrm{Rbt}$, serAsp, $\alpha=\mathrm{Es} / \mathrm{Eb}$, Es - modulus of elasticity of steel, Eb - initial tangent Modulus of concrete.

Since the duration of the dynamic action is $\mathrm{td}=0.028 \mathrm{sec}$ the reinforcing bar is strengthened. The ultimate dinamic force that destroy reinforcing bar is Ndult $=\varphi s \cdot R s$, ser $\cdot y s \cdot A s p=$ $1.65 \cdot 785 \cdot 1 \cdot 6.158=797.6 \mathrm{kN}>$ "N" "n-1" $\wedge " d "=$ $545.4 \mathrm{kN}$, where $\varphi s=1.65$ is a coefficient that takes into account the dynamic increase in the yield point and determined from the diagram $\varphi s$ - $\omega 0$ td [01]; $\omega 0=\mathrm{Es} / \mathrm{K} ; \mathrm{K}$ - modulus of viscous resistance of reinforcing bars.

Thus, as a result of instantaneous local destruction of the concrete matrix, the reinforcing bar of the tightening element of the large-panel folded shell with the accepted level of the initial controlled stresses $\sigma \mathrm{sp}=741.7 \mathrm{MPa}$ is not destroyed.

\section{REFERENCES}

1) Kolchunov V.I, Klyuyeva N.V., Androsova N.B. \& Bukhtiyarova A.S., (2014). Zhivuchest' zdaniy i sooruzheniy pri zaproyektnykh vozdeystviyakh [Survivability of buildings and structures under beyond design impacts]. Moscow: Publishing house ASV.

2) WengaJ., TanaK.H.\&Leeb C.K., (2017). Modeling progressive collapse of 2D reinforced concrete frames subject to column removal scenario.. Engineering Structures, 141, 126143. doi:10.1016/j.engstruct.2017.03.018

3) Xianzhong Zhao, Shen Yan, Yiyi Chen, Zhenyu Xu\& Yong Lu, (2017). Experimental study on progressive collapseresistant behavior of planar trusses.. Engineering Structures, 135, 104-116. doi:10.1016/j.engstruct.2016.12.013

4) Wenda Wang, Huawei Li\& Jingxuan Wang, (2017). Progressive collapse analysis of concrete-filled steel tubular column to steel beam connections using multi-scale model. Structures, 9, 123-133. doi:10.1016/ j.istruc.2016.10.004

5) Feng Miao\& Michel Ghosn, (2016). Reliability-based progressive collapse analysis of highway bridges. Structural Safety, 63, 3346. doi:10.1016/j.strusafe.2016.05.004

6) Fedorova N.V. \& Khalina T.A., (2017). Issledovaniye dinamicheskikh dogruzheniy $v$ zhelezobetonnykh konstruktivnykh sistemakh pri vnezapnykh strukturnykh perestroykakh [Research of dynamic stress increasing in reinforced concrete structural systems when structural rearrangements occurs suddenly]. Promyshlennoye i grazhdanskoye stroitel'stvo, 5, 45-49.

7) Dem'yanov A.I., Kolchunov VI.I., Senchenko D.S. \& Terskikh A.B., (2017). Raschetnaya model' statiko-dinamicheskogo deformirovaniya $v$ zhelezobetonnoy tsentral'no - rastyanutoy konstruktsii v moment razrusheniya betonnoy matritsy [A computational model of static-dynamic deformation in a reinforced concrete centrally-stretched structure at the moment of destruction of a concrete matrix]. Stroitel'stvo i rekonstruktsiya, 2, 3-9.

8) Geniyev G.A., Kolchunov V.I., Klyuyeva N.V. and etc., (2004). Prochnost' i deformativnost' zhelezobetonnykh konstruktsiy pri zaproyektnykh vozdeystviyakh [Strength and deformability of reinforced concrete structures under beyond-design effects]. Moscow: Publishing house ASV.

9) Gordon V. A.\& Kravtsova E. A., (2010). Pereraspredeleniye napryazhennosti $v$ slozhnoy sostavnoy balke pri degradatsii svyazey sdviga [Redistribution of stresses in a loaded composite beam during degradation of shear bonds]. Stroitel'naya mekhanika i raschet sooruzheniy, 4, 2-6.

10) Gordon V.A.\& Kravtsova E.A., (2012). Dinamicheskiye dogruzheniya $v$ balke $s$ raznourovnevymi potol'nymi rassloyeniyami [Dynamic force increasing in a beam with multilevel longitudinal cracks]. Stroitel'stvo i rekonstruktsiya, 6(44), 17-27.

11) Posobiye po proyektirovaniyu zhelezobetonnykh prostranstvennykh konstruktsiy pokrytiy i perekrytiy (k SP 52-117-2008 *) [Manual on the design of reinforced concrete spatial structures of coatings and overlappings (to SP 52-117-2008*)]. (2010). Moscow: SRIRC named after A.A. Gvozdev - Institute of JSC Science and Research Center Construction.

12) Kolchunov V.I., Pyatikrestovskiy K.P.\& Klyuyeva N.V., (2008). Prostranstvennyye konstruktsii pokrytiy: Uchebnoye posobiye [Spatial construction of coatings: a textbook]. Moscow: Publishing house ASV.

13) Svod pravil SP 63.13330.2012 Zhelezo- 
betonnyye konstruktsii. Osnovnyye polozheniya. Aktualizirovannaya redaktsiya SP 52-01-2003: Izdaniye ofitsial'noye [Code of Regulations SP 63.13330.2012 Reinforced concrete structures. Basic provisions. Updated version of SP 52-01-2003: official edition]. (2011). Moscow: Minregion.
Paper sent to revision: 21.07.2017.

Paper ready for publication: 14.09.2017. 